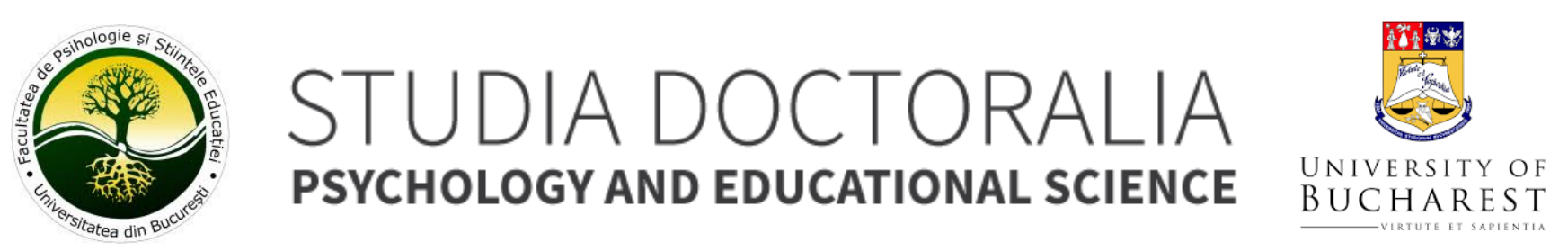

\title{
Predictors of the performance at the Baccalaureate in Romania. A Pilot Study
}

Cezar Valentin Ionescu

University of Bucharest, Department of Psychology

\section{ARTICLE INFO}

Article history:

Received 20-February-2018

Accepted 20-August-2018

Available online 15-September-2018

This article should be cited as:Ionescu, C. V. (2018). Predictors of performance at the Bacalaureate in Romania. A Pilot Study. Studia Doctoralia. Psychology and Educational Science, 16,7786.

This is an open access article under the CC BY license (http://creativecommons.org/licenses/by/4.0/).

Corresponding author at: University of Bucharest, Department of Psychology, 90 Panduri Av, Bucharest, Romania.

E-mail address: ionescu_cezar_valentin94@yahoo.com

\section{ABSTRACT}

The aim of the present study is to examine the predictors of performance on the Romanian Bacalaureat (BAC). The study analyses the relationship between the composite BAC score as the criterion and several psychological attributes as the predictors: general cognitive ability, emotional intelligence, learning motivation, grit, conscientiousness, self-regulation, and the hours spent on exam preparation. Data analysis reveals the fact that intelligence does not predict BAC performance at all. The same result also holds for the association between BAC performance and emotional intelligence or motivation. Self-regulation, conscientiousness and grit are trivially, yet not statistically significant associated with BAC performance. Even the number of hours spent on exam preparation donot predict BAC performance.Taking these results into account, it is crucial to explain why no statistically significant association was obtained between the predictors and criterion. In the author's mind, the findings should sound a warning with regard to the exam held in Romania when one graduates high school.

Keywords:Bacalaureate performance, intelligence, emotional intelligence, conscientiousness, grit, motivation, self-regulation, exam preparation

\section{INTRODUCTION}

This paper discusses the psychological predictors of performance at the maturity exam in Romania, which is called the Bacalaureate. The importance of this study is given by the alarming fluctuations in the past 10 years in this exam, with a promotion rate of $84.59 \%$ in 2004 and one of $56.44 \%$ in 2013 (according to media fax). Under such circumstances, it is important to evaluate the performance predictors for this exam at the national level to find out in whichaspects the grades in the Bacalaureate vary; in other words, who scores high at the Bacalaureate exam? What is interesting is that in other countries there are no such fluctuations in the maturity exam. Let's take the SAT as an example: average fluctuations in the past 
few years were about 4\% (North Carolina 2013 SAT report).

This draws attention to the Romanian exam - why do these fluctuations occur? Most likely, the cause is the testing methodology, but even so, it's important to find a commonality (if one exists) of predictive traits in order to know how to invest better in students to cope with of any kind of Bacalaureate. Assuming that intelligence is a good predictor of academic performance (Schneider \&Flanagan, 2015), we are aware that intelligence growth interventions are not a viable solution (Protzko, 2015), but we can invest more resources in people with lower intelligence to optimize their behavior to reach their potential). Therefore, the present research discusses various psychological variables that contribute, besides intelligence to a certain extent, to the students' performance at the Bacalaureate exam in Romania. Because it is among the few such studies in Romania, strictly referring to the relationships of these variables with the Baccalaureate examm this research has the character of a pilot exploratory study. However, the selection of variables for this study was conducted in an educated manner, based on the findings of comparable studies published in international journals with a high impact factor, focusing on those that had the SAT performance test criterion.

\section{Intelligence as a predictor of exam performance}

Intelligence is a general mental ability that involves, among other things, the ability to reason, plan, solve problems, abstract thinking, understand complex ideas, and learn from experience quickly. It's not a simple mechanical learning of information from a book or a specific academic field or the ability to do well in tests. Rather, it is an ability that makes individuals understand and give meaning to the surrounding world (Gottfredson, 1997). Intelligence is given by a score to a standardized test designed to measure the construct. The first historical use of such a score (IQ) is given in 1914 in a book by psychologist William Stern. More than a century ago, in 1904, Spearman ran a factorial analysis (Cattell,1952)for cognitive loaded school disciplines: mathematics, English, French, classics, music, and music disc discrimination. The results observed by Spearman showed that all scores correlate positively with each other, i.e., who gets a high score on a test tends to perform well in other tests as well; for example, people who obtained a good math score also obtained a good score in classical Latin, all of them having a common ability: a general factor of intelligence. The existence of a single measurement of cognitive abilities, namely the nominal existence of a general factor ( $\mathrm{g}$ factor) of intelligence, is already an orthodox perspective among specialists and the general public (Carroll, 1993; Gottfredson,1997; Jensen, 1998). Intelligence is the general ability to process (correctly and quickly) cognitive complexity, regardless of content (verbal, figurative, numeric) (Gottfredson, 1997). There are two basic assumptions about the current theory of intelligence: People are born with some potential of intelligence; Human intelligence can be measured (Gardner, 1998; Gottfredson, 1998).

Between SAT and g factor, numerous research has been done to establish the relationship of educational performance with different intelligent testing batteries, with substantial correlations observed: with the Armed Services Battery Vocational Aptitude Battery, a correlation of .82 (.86 non-linearity correction) (Morgan, 1990), and with the Raven Advanced Matrices, a correlation of 43 (.72 after correction for amplitude restriction) was found (Raven et al, 1998, Meredith, 2003). It correlates significantly with mathematical skills in the education system (Floyd et al, 2003).

Therefore, we assume:

H1: Intelligence correlates with the results of the Bacalaureate in Romania.

\section{Emotional intelligence as a predictor of exam performance}

Emotional intelligence is one of the most en vogue concepts in today's psychology. The definition of this concept and its implications are often poorly understood by unfamiliar public due to distorted media popularization. Currently, the dominant model of emotional intelligence is that of Mayer and Salovey (2002), being one of the most robust models. The model looks at emotional intelligence as an ability described by emotional recognition and abstract rationalization with information collected from the emotional level (Mayer \& Salovey, 1999). The model distinguishes four branches of emotional intelligence: emotion perception, the use of emotions, understanding emotions, emotion management. These abilities are placed in a hierarchical manner similar to the three layers developed by Carroll $(1993,2003,2005)$. Many authors assert that emotional intelligence is important in all areas of life and that it has a higher predictive value than IQ (Goleman, 1995), but the conceptualization and implications that Goleman puts in question have been harshly criticized. Goleman conceptualized emotional intelligence in desirable characteristics without empirical support for them (Cooper et al, 1997), so Goleman's approach remains pseudo-scientific in nature and has its own advertising orientation. Therefore, we have to look at what scientific studies tell us. The predictive value of emotional intelligence has been tested on psychology students compared to the five personality factors and IQ. It is true that emotional intelligence has predicted academic 
performance, but has not shown a very high incremental value over traditional cognitive tests (Barchard, 2003). Another study of an African-American women population has not identified any statistically significant link between the level of emotional intelligence and academic outcomes (Bradshaw, 2008). This is not idiosyncratic to the population because other similar studies have also been carried out without a correlation with academic performance (Cyr, 2006). This does not necessarily mean that there is no relationship. The aforementioned studies were conducted on a population already selected at the faculty; emotional intelligence can play an important role for high-risk individuals in high school (Kvapil, 2007). Positive correlation with academic performance persists in high school population (Marquez et al, 2006) than in higher education. Other studies reveal the importance of emotional intelligence at high school (Parker et al, 2004) and college (Parker et al, 2002). Assumptions for these fluctuations may range from amplitude restriction to irrelevance of the construct in the field.

Therefore, we want to test if:

H2: Emotional intelligence correlates with the results of the Bacalaureate in Romania.

\section{Conscientiousness as a predictor of exam performance}

Conscientiousness is a dimension of personality manifested by attributes such as meticulousness, ordering, vigilance, attention to detail, tenacity, patience, and perseverance (Thompson, 2008). This manifests in behavioral acts oriented toward systematizing and improving actions. For example, individuals with a high level of conscientiousness are attentive to detail, they also take notes in school, they prepare their school bag in the evening (DeYoung et al, 2002). Conscientious individuals are generally more laborers and more confident; they also tend to be more conformist.

Conscientiousness is of high importance in academic success (Higgins et al, 2007). It is the only dimension in the Big Five model, which once controlled the sphere of intelligence, it provides a predictive value for success in the workplace (Schmidt, 2004). In a meta-analysis carried out in 2009 on the relationship of the Big Five model of personality with academic performance, there was a positive correlation between conscientiousness and academic performance, and independence from the intelligence level (Poropat, 2009). A three-year longitudinal study at a UK university highlighted a correlation between Big Five neuroticism and conscientiousness with academic performance, where neuroticism predicted lack of performance and consciousness of high performance; this predicts $10 \%$ of the total variance (Chamorro-Premuzic \& Furnham, 2003).

Therefore:

H3: Conscientiousness correlates with performance at the Bacalaureate in Romania.

\section{Grit as a predictor of exam performance}

Grit is a personality or non-cognitive feature that often confuses with conscientiousness. This is about pursuing your long-term goals, coupled with the level of motivation needed to accomplish them. We define grit as being "perseverance and support for achieving long-term goals" (Duckworth, 2007). In studies of influential people, it is concluded that although the skills are very important, these individuals also have a far above average grit. Grit is a stable concept in time that does not require immediate positive feedback. Individuals with a high level of grit areable to maintain their level of motivation over time regardless of failure. Grit has two facets: the perseverance of effort and the consistency of interest (Duckworth, 2007). In essence, we can compare a person with a high grit, with a marathonist who continues to run despite the strain and muscle pain of the moment.

A topic investigated from the very beginning in the research of grit was that of people with equal intelligence but with different achievements (Duckworth, 2007). The two concepts are orthogonal, and grit has a slightly negative correlation with intelligence (Duckworth, 2009), which explains to some extent the differences in the outcome of people with the same level of intelligence.

There is a strong correlation with the constancy factor (Duckworth, 2009). The two constructs have a correlation of 0.86 at the genetic level, in a study conducted on monozygotic twins; in the same study, following a statistical control of personality factors, grit does not show an increase in the prediction of academic performance (Rimfeld et al, 2016). It is not entirely clear whether Grit has a separate existence from conscientiousness. Therefore,

H4: Grit correlates with performance at the Bacalaureate in Romania.

\section{Self-regulation as a predictor of exam performance}

Self-regulation refers to controlling and directing a person's thoughts, behaviors and emotions to achieve a proposed goal. The concept can be divided into four components: desirable behavior, motivation to achieve certain standards, monitoring and ambition (Baumeister\& Vohs, 2003). Studies show that this concept has a finite 
source of use, like a battery (Muraven\& Baumeister, 2000), distinguishing it from the concept of ambition.

Historically speaking, Albert Bandura (1991) has made a significant contribution to this concept. He believes that the concept of self regulation is one that controls human behavior, thus combining the cognitive component with the behavioral. Criticism of the concept wasprimarily focused on its operationalization. The self-regulation system is built from various difficult-to-integrate functions (Carver, 1990). Despite the criticism, the concept relates to many aspects of everyday life (Perry et al, 2006) and should not be neglected.

In spite of these findings, the focus of this paper is limited to the academic implications of the concept of selfregulation that integrates aspects such as metacognition, planning and motivation for learning (Butler, 1995). The process of self-regulation in education plays the role of self-evaluation and the establishment of strengths and weaknesses, as well as strategies one will put in place to achieve the maximum results in a specific situation. This concept is further differentiated from ambition, which is a superior regulator of human behavior, as mentioned above (metacognition). When students use self-regulation strategies to face challenges, they practice their way of learning and develop a deep understanding of the subject they are studying; this effort will give rise to academic success (Perry, 2006). As a result, individuals with a high level of self-regulation manifest a high level of self-efficacy.

The concept of place of control correlates significantly with academic performance and the concept of selfregulation (being to some extent a component of it, but not isomorphic), but these features do not arise independently from the academic environment in which the person breaks down. Self-regulation is also influenced by pupil-teacher interaction: the teacher encourages student performance and thus forms the necessary skills to continue (Whyte, 1978). The good news is that this concept can be developed; there is evidence that programs for the direction and development of self-regulation are particularly successful, especially those based on cognitive social theory.

H5: Self-regulation correlates with performance at Bacalaureate in Romania.

\section{Motivation as a predictor of exam performance}

Motivation is often used to label the ambition or perseverance of an individual; its connotation is predominantly positive, being a psychological construct often used in folklore (Maehr\& Maehr, 1997). The motivation has a high interest in the educational system, namely educational psychology, in principle, due to the involvement it is supposed to have in helping the pupil or the student to learn. The form of motivation in education is slightly different in quality than general motivation. Motivation for learning has facets that are strictly in the intellectual curiosity, being grouped with the desire to act on this epistemic curiosity. Although it is part of an individual's overall motivational factor, it would be a reluctance to consider that the two are isomorphic; this must be seen and analyzed separately. Motivation has different effects in terms of learning activity; it can be: directing a behavior to achieve a specific purpose, increasing effort and invested energy, persistence in activity, cognitive focus, attention to consequences (behaviorism) (Williams\& Stockdale, 2004). An interesting observation is that in the III grade to high school, intrinsic motivation decreases in the absence of knowledge of a clear cause, more precisely in the absence of the final purpose of this activity. Motivation or, at least, the perception of self-efficacy is positively correlated with academic performance (Zimmerman et al, 1992).

Academic motivation seems to be affected by the relationship with people of the same rank (with colleagues), suggesting that social influence on academic motivation is relatively important and should be considered when discussing the concept of academic motivation (Wentzel, 2005). Not only that, this information helps the idea that motivation contributes to academic performance in a positive way (Zimmerman et al, 1992) and can direct our attention to a possible improvement in performance by shaping the social environment to which children have access, namely the social component of the school.

H6: Learning motivation correlates with performance at the Bacalaureate in Romania.

\section{Tutoring and preparation for the Bacalaureate}

Although not a psychological variable, exam preparationplays a crucial role in the Romanian pupil's path to the Bacalaureate exam, so it should not be ignored in this study. Considering the absence of any analysis of the effect of preparation or tutoring on academic performance and the general appreciation of common or logical knowledge, the planning decisions are not perfectly rational and suffer from the influence of various cognitive biases (Barnes, 1984). However, there are studies that provide evidence for the positive relationship between preparation and the grades scored in the Bacalaureate. These studies were done in relation to the SAT test, which supports the idea that a greater amount of tutoring leads to an increase in the result at this exam (Messick, 1981).

In a comparative analysis between the students who received preparation and those who did not, there was again a positive correlation with SAT grades in favor of 
those who received preparation, but the criticism of this study was that it was largely an observational one (Hansen, 2004). Following the models previously exposed, we should be able to extend these models to the Bacalaureate exam in Romania. There is also the possibility that a strong familiarity with the exam content may lead to a positive relationship of the baccalaureate grades. This can lead to a compromise of predictability, for example if we repeat a task many times and then we are tested on the skills in our task, we will notice a relatively artificial increase of our ability in the field (Arendasy, 2016).

H7: The number of preparation hours correlates with the students' performance at the Bacalaureate in Romania.

As mentioned earlier, intelligence seems to be the best predictor of performace. Next, we will report on BAC performance, taking into account the combined effect of intelligence with each predictor investigated.

H8: The combined effect of intelligence with $E Q$ explains better the variance of Bacalaureate grades than intelligence.

\section{METHODOLOGY}

\section{Participants and procedure}

A sample of 156 Romanian people aged 18-29 ( $M=22 ; S D$ $=2.17$ ) who have taken the Baccalaureate in Romania participated in this study. There is an equal gender variation. The invitation to participate in the study was launched in the online environment. After receiving email addresses from people who wanted to participate, e-mail invitations for the tests were emailed to them.

\section{Instruments}

Intelligence. For the measurement of cognitive ability, the General Ability Measure for Adults test (Naglieri, 1997) was used. The test consists of 66 items. The administration time is set at 25 minutes. At the end, a global IQ score is provided, as well as the scores for each of the subtests. Each item has 6 response options, of which only one is correct and the difficulty of the items is progressive.

Emotional intelligence. The Mayer-Salovey-Caruso Emotional Intelligence Test (MSCEIT) is a test of emotional intelligence from an aptitude perspective on the construct, with correct and wrong answers. MSCEIT comprises 141 items and requires a 30-45-minute completion time.

Motivation. Achievement Motivation Inventory (AMI) is a diagnostic procedure with a very wide applicability. The test
H9: The combined effect of intelligence with conscientiousness explains better the variance of notes to Bacalaureate than intelligence.

H10: The combined effect of intelligence with grit explains better the variance of Bacalaureate grades than intelligence.

H11: The combined effect of intelligence withselfregulation explains better the variance of Bacalaureate grades than intelligence.

H12: The combined effect of intelligence with the number of hours of preparation explains better the variance of Bacalaureate grades than intelligence.

provides a global score as well as 17 different scales with their individual score. The 17 scales AMI: BEPerseverance, DO- Dominant, EN- Commitment, EZ Safety of success, FX- Flexibility, FL- Absorption, FUFearless, IN- Intimacy, KA- Compensatory effort, LS- Pride of performance, Willingness to learn, SP- Preference for difficulty, SE- Independence, SK- Self-control and selfdiscipline, ST- Statutory orientation, WE- Focus on competitiveness, ZS- Goal setting.

Self-regulation. The Self-Regulation Questioner (SRQ) is a questionnaire designed to measure the self-regulation concept. The test is based on the Miller and Brown model $(1991 ; 1998)$ in this model. The test contains 63 questions on the Likert scale from 1 to 5 . Internal consistency is again very high $(\alpha=.91)$ (Aubrey, Brown, \& Miller, 1994).

Grit. Short grit scale is an inventory designed to measure no cognitive trait called ambition. It is composed of 12 items that present a series of statements that can respond from 1 to 5 with the degree of agreement on the statement. A fairly high internal consistency was found $(\alpha=.85)$.

Conscientiousness. A conscientiousness test of 20 items with an internal consistency of 0.87 (95\% Cl: $0.84-0.89$ IPIP) was applied. The test is subsumed to the Big Five personality model (http://www.researchcentral.ro).

\section{RESULTS}


The data was analyzed using the SPSS version 20 program, the data being previously gathered in a Microsoft Excel database.

An analysis of the Cronbach alpha internal consistency was carried out on all three tests translated by author. The internal consistency was computed after Cronbach (1951), formula: $\mathrm{a}=\frac{K}{K-1} \mathrm{x}\left(1-\frac{\sum_{i=1}^{k} x \delta y i^{2}}{\delta x^{2}}\right)$, where $\mathrm{K}=$ number of

Table 1. Reliability coefficients items, $\sigma \_x^{2}=$ the observed total variance of the score, $\sigma_{-} Y i^{2}=$ the variance of the component $i$ in relation to the rest of the items.

An acceptable internal consistency $(\alpha=0.74)$ was reported for the grit scale test, a high internal consistency $(\alpha=0.91)$ was also obtained for Self Test Questionar (SRQ) again obtained a very high internal consistency score $(a=0.92)$ (Popa, 2008), for details see Table 1.

\begin{tabular}{ccc}
\hline & Cronbach Alfa & $\mathrm{N}$ items \\
\hline Grit & $\mathrm{a}=0.74$ & $\mathrm{~N}=12$ \\
Conscientiousness & $\mathrm{a}=0.90$ & $\mathrm{~N}=20$ \\
SRQ & $\mathrm{a}=0.90$ & $\mathrm{~N}=63$ \\
\hline
\end{tabular}

Below we present the descriptive statistics of these data, such as the average, the standard deviation, the skewness and kurtosis distributions. These indicators are reported for each test as well as for the criterion (note from Baccalaureate in Romania), The GAMA test ( $N=124, M=$ $105, S D=12$, skewness $=-82$, kurtosis $=1.78$ ) is very close to the original test (Naglieri, 1997). The MSCEIT test $(N=123, M=106, S D=10$, skewness $=-1.35$, kurtosis $=$ 3), AMl questionnaire $(N=128, M=101, S D=8$, skewness $=32$, kurtosis $=3)$, the SRQ questionnaire $(N=$ $155, M=292, S D=29$, skewness $=-4.82$, kurtosis $=30$ ), Grit questionnaire $(N=155, M=60$, skewness $=57$, kurtosis $=.62$ ), the meditations for Baccalaureate in Romania (skewness $=10.65$, kurtosis $=124.82$ ) and the criterion for which these average predictions were made in Bacalaureate $(N=155, M=8.65, S D=1$, skewness = 1.29 , kurtosis $=2.97$ ) of these data see Table 2 .

Table 2. Descriptive statistics

\begin{tabular}{cccccc}
\hline & $N$ & $M$ & $S D$ & Skewness & Kurtosis \\
\hline GAMA & 124 & 105 & 12 & -.82 & 1.78 \\
MSCEIT & 123 & 106 & 10 & -1.35 & 3 \\
AMI & 128 & 101 & 8 & .43 & .79 \\
SRQ & 155 & 292 & 29 & -4.82 & 30 \\
Grit & 155 & 60 & 6 & 3.35 & 18.39 \\
Conscientiousness & 155 & 83 & 7 & -.57 & .62 \\
Preparation & 155 & 71 & 239 & 10.65 & 124.82 \\
Bac. grade & 155 & 8,65 & 1 & -1.29 & 2.97 \\
Total & 119 & & & &
\end{tabular}

Formulasof skewness and kurtosis are presented below:

Skewness $=1 / n \sum_{-}(i=1)^{\wedge} n(X i-X) /(\operatorname{SD}(x) 3$

Where $n=$ number of items, $S D=$ standard deviation and $\mathrm{X}=$ average and $\mathrm{X}=$ median;

Kurtosis $=\left(\left(\sum_{-}(i=1)^{\wedge} n(Y i-Y) 4\right)\right) /(N-1) S^{\wedge} 4$

Where $\mathrm{n}=$ number of items, $\mathrm{Yi}=$ mean, $\mathrm{Y}=$ median, $\mathrm{S}=$ standard deviation.

A linear regression was conducted to establish the relationship between the predictor and the academic performance at the Baccalaureate exam in Romania. Preparation correlated with the average at Bacalaureat, a null correlation $(r=-0.06 ; p>.05)$, statistically insignificant, in the case of self-regulation was again obtained a null correlation $(r=.05 ; p>.05)$, a slight positive correlation $(r=$ .10; $p>.05$ ) but insignificant from a statistical point of view has also been observed, a positive correlation has also been obtained between ambition and performance at Bacalaureat $r=.14 ; p>.05$ ), but this was not statistically significant, between the level of intelligence measured by the GAMA and Bacalaureat test, a perfect null correlation ( $r$ $=.00, p>.05$ ) was obtained, between the score at MSCEIT and the maturity exam obtained a null correlation $(r=-.03$; $p>.05)$. Finally, there was a new correlation between the $\mathrm{AMI}$ and Bacalaureat test $(r=.02 ; p>.05)$.

The formula for linear regression is as follows:

$\mathrm{Y}^{\wedge}=\mathrm{bX}+\mathrm{a}$ 
Where $Y=$ predicted value of $y, b=$ regression slope, $a=$ origin point in $\mathrm{y}$ where $\mathrm{x}=0$.

Following this analysis, a moderation relation of the IQ effect, measured by the GAMA test, was carried out by means of various variables such as $E Q$, measured by the
MSCEIT test $(\mathrm{B}=-.00 ; \Delta \mathrm{R} 2=.00 ; \mathrm{p}>.05)$ but with a statistically insignificant correlation, followed by variable conscientiousness $(B=.01 ; \Delta R 2=.02 ; p>.05)$, than ambition $(B=.02 ; \quad \Delta R 2=.02 ; \quad p>.05)$, preparation hours $(B=.00$; $\Delta R 2=.00 ; p>.05)$, and self-regulation $(B=.06 ; \Delta R 2=.00$; $p>.05)$. Reliability coefficients can be seen in Table 1.

Table 3. Pearson correlations

\begin{tabular}{lllllllll}
\hline & 1 & 2 & 3 & 4 & 5 & 6 & 7 & 8 \\
\hline 1. Bac Grade & -.06 & & & & & & & \\
2. Preparation & -.05 & & & & & & & \\
3. SRQ & .10 & .17 & & & & & & \\
4. Conscientiousness & .10 & .13 & 46 & & & & & \\
5. Grit & .14 & .07 & 26 & .17 & & & & \\
6. Intelligence & .00 & .10 & 17 & .03 & 10 & & & \\
7. Emotional Intelligence & -.03 & -.02 & 20 & -.07 & 01 & .01 & & \\
8. Motivation & .02 & -.01 & 33 & .20 & 30 & 11 & 09 & \\
\hline
\end{tabular}

Table 4. Model fit

\begin{tabular}{cccccccc}
\hline Model & $\mathrm{R}$ & $\mathrm{R}^{2}$ & $\mathrm{SEE}$ & $\mathrm{df1}+\mathrm{df2}$ & $\mathrm{Fig}$ & $\begin{array}{c}\text { Dubin- } \\
\text { Watson }\end{array}$ \\
\hline 1 & .23 & .05 & .94 & {$[7 ; 111]$} & .50 & 2.05 \\
\hline
\end{tabular}

Table 5. Combined effect on Bac performance

\begin{tabular}{|c|c|c|c|c|c|c|c|c|}
\hline \multirow[t]{2}{*}{ Model } & B & SE & $\beta^{a}$ & & $\Delta$ & & V & Tolerance \\
\hline & \multicolumn{2}{|c|}{ B } & & $\mathrm{R}^{2}$ & & IF & & \\
\hline GAMA $x$ & -.00 & .00 & -.02 & & .0 & & 1 & 1 \\
\hline MSCEIT & & & & 0 & & & & \\
\hline GAMA $x$ & .01 & .01 & .14 & & .0 & & 1 & .99 \\
\hline Consc. & & & & 2 & & & & \\
\hline GAMA x Grit & .02 & .01 & .15 & 2 & .0 & & 1 & .99 \\
\hline GAMA $x$ & .00 & .00 & -.06 & & .0 & & 1 & .99 \\
\hline Prep. & & & & 0 & & & & \\
\hline $\begin{array}{l}\text { GAMA x } \\
\text { SRO }\end{array}$ & .00 & .00 & .04 & 0 & .0 & & 1 & .99 \\
\hline
\end{tabular}

\section{DISCUSSION}

Following the data analyses and its overlap with the hypotheses of the research, we concluded that all the hypotheses were invalidated. This is interesting, given the manner in which hypotheses were built. These have been based on available literature at the current level, focusing on the relationships between different psychological variables and academic performance. As the Baccalaureate test is an academic performance test, we expected that the observed relationships would also appear, but this did not happen in the present research; the question remains as to why the Baccalaureate in Romania does not show these relationships? One of the immediate explanations would be that the sample is too small to detect consistent bindings, but this is not entirely viable, given that the correlation obtained is approximately 0 ; even on a small sample we had to get some general trend (upwardly preferable). This can be explained in several ways. One would be that the Romanian population has 
idiosyncratic characteristics different from the rest of the world, thus not establishing this link. This is obviously false, given the absence of a different evolutionary environment to create net selection pressures different in this country compared to others (Buss, 2008; Darwin, 2009). Such hypothesis has no rational meaning. Another option would be to look at the other point of the relationship, namely the Baccalaureate exam itself, and why it does not have a correlation with the intelligence and the other variables, namely the structure in which it is built, given that the majority tests are marked by teachers; this leaves room for a wide range of variability ranging from indulgent to the most harsh judgement by the teachers. These differences also show at the high school level, where marking for top ranking high schools will place more emphasis on detail, but this is not the case at lower ranking schools. This is a possible explanation that needs to be further investigated to be supported by evidence.

This research has a purely descriptive role: it does not intend to give a positive or negative connotation to the Baccalaureate exam but rather to identify the mechanisms that could predict performance. It should not be interpreted as an attack on the educational system, but rather as an opportunity for development. Therefore, the information presented in this research should be strictly understood in an informative manner; and it does not aim to support any political party or state initiative / education reform. Therefore, due to its neutral character, it can be used for various purposes that often go beyond initial purposes. The fundamental contribution is to science, namely to help develop the cross-cultural educational paradigm in the field of psychology by synchronizing the Romanian research with the international one.

\section{Limitations and future directions}

\section{REFERENCES}

Arendasy, M. E., Sommer, M., Gutiérrez-Lobos, K., \& Punter, J. F. (2016). Do individual differences in test preparation compromise the measurement fairness of admission tests? Intelligence, 55, 44-56.

Aubrey, L. L., Brown, J. M., \& Miller, W. R. (1994). Psychometric properties of a selfregulation questionnaire (SRQ). Alcoholism: Clinical \& Experimental Research, 18, 429.
Finally, we should analyze the absence of these relationships from a holistic perspective and mention possible limitations of the research. Perhaps the relationship exists, but the sample is too small, as suggested by Arthur Connan Doyle (1981) who stated that: the absence of evidence is not evidence of absence.

In the present study, sampling was carried out as a result of volunteer option for study participants, without performing a randomization of them from a particular population. The "anything goes" technique (Feyerabend, 1975) was applied. Thus, the sample was probably not representative of the population in Romania, but it was a convenient one. Since people self-select, various mistaken variables, such as agreeableness, may appear.

Given that participants were allowed to choose their test conditions themselves, we can say that they are an additional variable in the field. The Internet connection itself is a problem, especially for the GAMA test, which has a time limit. Some individuals may have taken the test under less optimal conditions, such as late hours, in noisy environments, after a sleepless night, etc.

The effects of the predictor variables (IQ, EQ, motivation, conscientiousness, ambition, selfregulation, number of preparation hours) may have been limited, since all individuals who applied for research have graduated the Baccalaureate. Thus, an important portion of the society we live in, namely students who failed the Bacalaureate, was not considered.

Information obtained from this research can be used to regulate / optimize primary and secondary education in Romania. Measures may be taken to take advantage of the various characteristics of the pupils in order to obtain better results at the Baccalaureate in Romania. Also, the examcould be changedto better align with the Western norm.

Bandura, A. (1991). Social cognitive theory of selfregulation. Organizational Behavior and Human Decision Processes, 50(2), 248-287.

Barchard, K. A. (2003). Does emotional intelligence assist in the prediction of academic success? Educational and Psychological Measurement, 63(5), 840-858.

Barnes, J. H. (1984). Cognitive biases and their impact on strategic planning.Strategic Management Journal, 5(2), 129-137. 
Baumeister, R. F., \& Vohs, K. D. (2003). Selfregulation and the executive function of the self. Handbook of Self and Identity, 1, 197-217.

Bradshaw, F.B. (2008). Exploring the relationship between emotional intelligence and academic achievement in African American female college students. Dissertation Abstracts International:Section A: Humanities and Social Sciences, 69(3-A), 871.

Buss, D. M. (2008). The Evolution of Desire-Revised. New York: Basic Books.

Butler, D. L., \& Winne, P. H. (1995). Feedback and self-regulated learning: A theoretical synthesis. Review of Educational Research, 65(3), 245-281.

Carroll, J. B. (1993). Human cognitive abilities: A survey of factor-analytic studies. Cambridge: University Press.

Carroll, J. B. (2003). The higher stratum structure of cognitive abilities: Current evidence supports $g$ and about ten broad factors. In H. Nyborg (Ed.), The scientific study of generalintelligence: Tribute to Arthur $R$. Jensen. New York: Pergamon.

Carroll, J. B. (2005). The three-stratum theory of cognitive abilities. In D. P. Flanagan, J L. Genshaft, \& P. L. Harrison (Eds.), Contemporary intellectual assessment: Theories, tests, and issues. New York, NY:Guilford Press.

Carver, C. S., \& Scheier, M. (1990). Principles of selfregulation: Action and emotion. Guilford Press.

Cattell, R. B. (1952). Factor analysis. New York: Harper.

Chamorro-Premuzic, T., Furnham, A. (2003). Personality traits and academic examination performance. European Journal of Personality, 17(3), 237-250.

Cooper, R. K., Sawaf, A., Labovitz, G. H., \& Rosansky, V. (1997). Executive EQ. Audio-Tech Business Book Summaries.

Costa, P. T. \& McCrae, R. R. (1992). NEO personality Inventory professional manual. Odessa, $\mathrm{FL}$ : Psychological Assessment Resources.

Cox, C.M. (1926). Genetic studies of genius: Vol. 2. The early mental traits of three hundred geniuses. Stanford, CA: Stanford University Press.

Cyr, J. (2006). Emotional intelligence as a predictor of performance in college courses. Dissertation Abstracts International: Section B, 67 (09).
DeYoung, C. G., Peterson, J. B., \& Higgins, D. M. (2002). Higher-order factors of the

Big Five predict conformity: Are there neuroses of health? Personality and Individual Differences, 33, 533-552.

Duckworth, A.L. \& Quinn, P.D. (2009). Development and validation of the Short Grit Scale (GRIT-S). Journal of Personality Assessment, Vol 91(2), pp. 166-174.

Duckworth, A.L., Peterson, C., Matthews, M.D., \& Kelly, D.R. (2007). Grit: Perseverance and passion for long-term goals. Journal of Personality and Social Psychology, 92 (6), p. 1087.

Floyd, R. G., Evans, J. J., \& McGrew, K. S. (2003). Relations between measures of Cattell-Horn-Carroll (CHC) cognitive abilities and mathematics achievement across the school-age years. Psychology in the Schools, 40(2), 155-171.

Gardner, H.(1998). A multiplicity of intelligences. Scientific American Presents Intelligence, 9.

Goleman, D. (1995). Emotional Intelligence: Why It Can Matter More Than IQ. New York: Bantam Books.

Gottfredson, L. S. (1997). Why g matters: The complexity of everyday life. Intelligence, 24, 79-132.

Gottfredson, L. S. (1998). The general intelligence factor. Scientljk American Presents, 11.

Hansen, B. B. (2004). Full matching in an observational study of coaching for the SAT. Journal of the American Statistical Association, 99(467), 609618.

Higgins, D. M., Peterson, J.B., Lee, A., Pihl, R.O. (2007). Prefrontal cognitive ability, intelligence, Big Five personality and the prediction of advanced academic and workplace performance. Journal of Personality and Social Psychology, 93(2), 298-319.

Jensen, A. R. (1998). The $g$ factor: The science of mental ability. Westport, CT: Praeger.

Kvapil, L. (2007). The impact of emotional intelligence on the academic performance of at-risk high school students. Dissertation Abstracts International: Section A: Humanities and Social Sciences,68(3-A), 942.

Maehr, M. L., \& Meyer, H. A. (1997). Understanding motivation and schooling: Where we've been, where we are, and where we need to go. Educational Psychology Review, 9(4), 371-409. 
Márquez, P. G., Martín, R.P., \& Brackett, M.A. (2006). Relating emotional intelligence to social competence and academic achievement in high school students. Psicothema, 18, 118-123.

Mayer, J.D., \& Salovey, P. (1997). What is emotional intelligence? In P. Salovey \& D. Sluyter (Eds.), Emotional development and emotional intelligence: Implications for educators (pp. 3-31). New York: Basic Books.

Messick, S., \& Jungeblut, A. (1981). Time and method in coaching for the SAT. Psychological Bulletin, 89(2), 191.

Morgan, R. (1990). Analyses of the predictive validity of the SAT and high school grades from 1976 to 1985. In W.W. Willingham, C. Lewis, R. Morgan, \& L. Ramist (Eds.), Predicting college grades: An analysis of institutional trends over two decades (pp. 195212). Princeton, NJ: Educational Testing Service.

Muraven, M., Baumeister, R. (2000). "Self-Regulation and Depletion of Limited Resources: Does SelfControl Resemble a Muscle?". American Psychological Association.

Parker, J. D., Creque, R. E., Barnhart, D. L., Harris, J. I., Majeski, S. A., Wood, L. M., Bond, B. J.\& Hogan, M. J. (2004). Academic achievement in high school: does emotional intelligence matter? Personality and Individual Differences,37(7), 1321-1330.

Parker, J. D., Summerfeldt, L. J., Hogan, M. J., \& Majeski, S. A. (2002). Emotional intelligence and academic success: Examining the transition from high school to university. Personality and individual differences, 36(1).

Perry, N.E., Phillips, L., \& Hutchinson, L.R. (2006). Preparing student teachers to support for selfregulated learning. Elementary School Journal, 106, 237-254.

Poropat, A. E. (2009). A meta-analysis of the fivefactor model of personality and academic performance. Psychological bulletin, 135(2), 322.
Protzko, J. (2015). The environment in raising early intelligence: A meta-analysis of the fadeout effect. Intelligence, 53, 202-210.

Raven, J., Raven, J.C., \& Court, J.H. (1998). Raven Manual: Sec. 4. Advanced Progressive Matrices (1998 ed.). Oxford, England: Oxford Psychologists Press.

Rimfeld, K., Kovas, Y., Dale, P.S., Plomin, R. (2016). True Grit and Genetics: Predicting Academic Achievement From Personality. Journal of Personality and Social Psychology.

Schmidt, F. L., Hunter, J. (2004).General Mental Ability in the World of Work: Occupational Attainment and Job Performance. Journal of Personality and Social Psychology, 86(1), 162-173.

Schneider, W. J., \& Flanagan, D. P. (2015). The relationship between theories of intelligence and intelligence tests. In Handbook of Intelligence (pp. 317-340). Springer New York.

Thompson, E.R. (2008). Development and validation of an international English big-five minimarkers. Personality and Individual Differences, 45(6), 542-548.

Wentzel, K. R. (2005). Peer relationships, motivation, and academic performance at school. Handbook of competence and motivation, 279-296.

Whyte, C.B. (1978). Effective Counseling Methods for High-Risk College Freshmen.Measurement and Evaluation in Guidance, 10(4), 198-200.

Williams, R. L., \& Stockdale, S. L. (2004). Classroom motivation strategies for prospective teachers. The teacher educator, 39(3), 212-230.

Zimmerman, B. J., Bandura, A., \& Martinez-Pons, M. (1992). Self-motivation for academic attainment: The role of self-efficacy beliefs and personal goal setting. American Educational Research Journal, 29(3), 663-676. 